\title{
Low plasma triiodothyronine concentrations and outcome in preterm infants
}

\author{
A LUCAS, ${ }^{*} \dagger$ J RENNIE, ${ }^{*}$ B A BAKER, ${ }^{*}$ AND R MORLEY* \\ *MRC Dunn Nutrition Unit and TUniversity Department of Paediatrics, Cambridge
}

SUMMARY A major association has been found between low plasma triiodothyronine concentrations in preterm neonates and their later developmental outcome. Plasma triiodothyronine concentration was measured longitudinally in 280 preterm infants below $1850 \mathrm{~g}$ birth weight. Babies whose lowest recorded concentration was $<0.3 \mathrm{nmol} / 1$ had, at $18 \mathrm{months}$ corrected age, 8.3 and 7.4 point disadvantages in Bayley mental and motor scales and a 8.6 point disadvantage on the academic scale of Developmental Profile II, even after adjusting for a range of antenatal and neonatal factors known to influence later development. Low concentrations of triiodothyronine were strongly associated with infant mortality, but not after adjusting for the presence of respiratory illness. There was no association between plasma triiodothyronine concentrations and somatic growth up to 18 months, and no association with necrotising enterocolitis or later cerebral palsy. Data on postnatal changes in plasma triiodothyronine concentrations are presented for reference purposes. While cited reference ranges for plasma triiodothyronine concentration appear suitable for well infants above $1500 \mathrm{~g}$ birth weight, smaller or ill babies often have very low values for many weeks. Our data are relevant to the debate on endocrine 'replacement' treatment in premature babies.

Triiodothyronine has about three to four times the metabolic potency of thyroxine and is formed by monodeiodination of thyroxine in tissues. Fetal tissues seem incapable of this step until relatively late in gestation ${ }^{1}$; hence plasma triiodothyronine concentration is very low in the human fetus before 30 weeks' gestation. ${ }^{2-4}$ A number of investigators have shown that plasma triiodothyronine concentrations rise postnatally in infants born preterm, but in the early postpartum period values are below the normal range for full term infants and adults. ${ }^{5-8}$ In some studies plasma triiodothyronine and thyroxine concentrations have been even lower in neonates with respiratory disease, ${ }^{9} 10$ suggesting that, as in adult 'euthyroid sick syndrome',11 severe systemic illness may depress thyroid function further.

Thyroid hormones play a critical part in the normal development of the lung, ${ }^{12-14}$ gut, ${ }^{15}$ and brain ${ }^{16-18}$; and the possibility that 'replacement' treatment in preterm infants could have favourable effects both in the short and longer term has been investigated by several groups. ${ }^{\text {9-21 }}$ It has been difficult to establish, however, that low plasma concentrations of thyroid hormones, in this special circumstance, reflect a deficiency state. Schonberger et al report a reduction in mortality rates of preterm infants given triiodothyronine and thyroxine in the neonatal period. ${ }^{20}$ In other studies, no outcome advantages have emerged, for instance, in early growth or later development. ${ }^{19} 21$

In this follow up study, we have related plasma triiodothyronine concentration, measured longitudinally in 280 preterm infants, to growth, major morbidity, mortality, and neurodevelopmental outcome to 18 months' post term.

\section{Patients and methods}

A total of 280 infants, birth weights under $1850 \mathrm{~g}$, were studied. Mean (SE) birth weight was $1330(18) \mathrm{g}$ and gestation $30.3(0.2)$ weeks. These infants had been enrolled in a larger preterm infant feeding trial for which extensive data were collected on antenatal, perinatal, and postnatal factors. ${ }^{22}$

Plasma triiodothyronine concentrations were assayed on plasma samples taken while the infants were in the special care baby unit in Cambridge, Ipswich, King's Lynn, Norwich, and Sheffield in the three year period, 1982-4. Plasma samples were collected in cooled tubes, centrifuged at $4^{\circ} \mathrm{C}$ within 
30 minutes and the separated plasma was stored at $-20^{\circ} \mathrm{C}$. Triiodothyronine was measured on 928 samples using a sensitive and specific radioimmunoassay (Gamma-B T3 Kit, RIA (UK)). Other thyroid hormones were not measured in this study.

Surviving infants were invited to a follow up examination at 18 months from expected date of delivery. All infants from the East Anglian centres ( $97 \%$ follow up rate on survivors) were examined by RM, who also organised the follow up in Sheffield. A medical and developmental history and full physical and neurological examinations were undertaken for each infant. Head circumference, naked weight, and supine length were measured and the Bayley mental and motor scales were administered to each infant ${ }^{23}$; the scores were calculated using the infant's age from expected date of delivery. The Bayley mental scale, however, like most tests of mental ability in young children, requires age appropriate manipulative skills and therefore children with cerebral palsy cannot be assessed satisfactorily. A further questionnaire based test was applied: the academic scale of Developmental Profile II ${ }^{24}$ which is based on items largely independent of fine manipulative skills at this age and permitted inclusion of infants with cerebral palsy. This test was used to derive an 'IQ equivalent'.

Statistical analyses included multiple regression, logistic regression, $\chi^{2}$ test, Student's $t$ test, and the Mann-Whitney rank sum test.

\section{Results}

In this cohort of 280 infants below $1850 \mathrm{~g}$ birth weight, plasma samples were analysed for triiodothyronine concentrations at 1-3 days, 4-7 days, and then at weekly intervals until discharge from hospital or until they attained $2000 \mathrm{~g}$ body weight. As not all infants contributed to the data at each time period and because they spent varying lengths of time in the study, data have been treated as cross sectional.

Plasma triiodothyronine concentrations were low in the first three days postnatally, median (lower quartile, upper quartile) $0.40(0.28,0.63) \mathrm{nmol} / \mathrm{l}$. By the fourth week, median triiodothyronine concentrations had risen more than twofold to $0.86(0.63$, $1 \cdot 17) \mathrm{nmol} / 1(\mathrm{p}<0.0001)$ and, in those infants still remaining in hospital, they rose further to $1 \cdot 20$, $(0.86,1.45) \mathrm{nmol} / \mathrm{l}$ beyond eight weeks $(\mathrm{p}<0.01)$.

Fig 1 shows that infants above and below $1200 \mathrm{~g}$ differed in plasma triiodothyronine concentration. In the first three days, the smaller infants had significantly lower median triiodothyronine values: $0.31(0.15,0.45) \mathrm{nmol} / \mathrm{l}$ compared with $0.48(0.34$, $0.68) \mathrm{nmol} / \mathrm{l}$ in the infants of larger birthweight

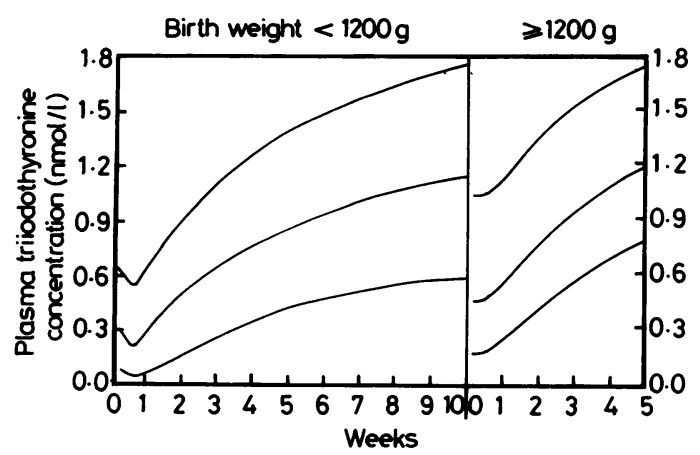

Fig 1 Postnatal changes in plasma triiodothyronine concentrations in preterm infants above and below $1200 \mathrm{~g}$; the smoothed curves presented are the 10th, 50th, and 90th centiles.

$(p<0.005)$. The rate of rise of plasma triiodothyronine postnatally was related to birth weight: in infants under $1200 \mathrm{~g}$ birth weight, plasma triiodothyronine concentration rose by a mean (SE) of $0.11(0.01) \mathrm{nmol} /$ week compared with a gain of 0.17 $(0.01) \mathrm{nmol} / \mathrm{week}$ in those with birth weight $\geqslant 1200 \mathrm{~g}$ $(\mathrm{p}<0.02)$. Median plasma triiodothyronine concen trations tended to fall during the first week in infanto below $1200 \mathrm{~g}$ (see fig 1). Though this fall did not reach significance, $77 \%$ of individual infants below $1200 \mathrm{~g}$, and $50 \%$ of those above $1200 \mathrm{~g}$, showed a fall in plasma triiodothyronine concentration rather than a rise during the first week. More detailed analysis, however, failed to show that this fall was more likely to occur in infants with severe lung disease, requiring mechanical ventilation for more than five days.

A reference lower limit of normal triiodothyronine concentration of $0.7 \mathrm{nmol} / 1$ for premature babies beyond 14 days $^{5}$ was achieved by the fourth week in $100 \%$ of healthy (non-ventilated) infants over $1500 \mathrm{~g}$ and in $81 \%$ of non-ventilated babies above $1200 \mathrm{~g}$; but in sick ventilated babies below $1200 \mathrm{~g}$ only $34 \%$ had achieved this value.

A number of factors were analysed for their relationship with the lowest recorded values of plasma triiodothyronine in each of the 280 subjects. In a regression model with the number of days of $N$ ventilation, birth weight, gestation, sex, mode of delivery (vaginal compared with caesarean), Apgar score at 5 minutes, and maternal toxaemia as independent variables, it was found that duration of ventilation $(\mathrm{p}<0.0001)$, low birth weight $(\mathrm{p}<0.001)$, and vaginal delivery $(p<0.03)$ were independently associated with lower plasma triiodothyronine concentration (dependent variable); see table 1 . In addition, when plasma triiodothyronine was coded 
Table 1 Summary of factors examined for their relationship with low plasma triiodothyronine concentration (lowest recorded concentration under $0.3 \mathrm{nmol} / \mathrm{l})$

Factors independently associated with low plasma triiodothyronine ${ }^{*}$ Low birth weight

No of days of ventilation

Death, to 18 months $\dagger$

Mental and motor developmental scores at 18 months (see table 2).

Vaginal delivery

Factors not associated with low plasma triiodothyronine

Weight, length, and head circumference gain in neonatal period

Weight, length, and head circumference at 18 months

Small for dates

Sex

Necrotising enterocolitis

Cerebral palsy

*After adjustment for key antenatal and neonatal factors.

†Association not significant after adjustment for differences in requirement for mechanical ventilation between infants with high and low plasma triiodothyronine concentrations.

as a dichotomous variable (see below), a plasma triiodothyronine concentration of under $0.3 \mathrm{nmol} / \mathrm{l}$ was less likely to occur in babies whose mothers had been given steroids before delivery (using logistic regression, $\mathrm{p}<0.02$ ).

Mental development (measured by the Bayley mental scale) at 18 months was the principal outcome response of interest in this study. In a preliminary analysis, the lowest triiodothyronine concentration recorded for each subject was a better predictor of later development than the value at any particular postnatal age or the rate of rise of plasma triiodothyronine concentrations postnatally. Analysis of raw data showed a significant relationship between mental developmental index and the lowest triiodothyronine concentration recorded, but this relationship was non-linear as shown in fig 2 with the scores rising sharply when minimum triiodothyronine concentrations exceeded $0.3 \mathrm{nmol} / \mathrm{l}$. The mean (SE) score in infants with triiodothyronine concentrations under $0.3 \mathrm{nmol} / \mathrm{l}$ was $92.3(3.1)$ compared with a mean of $102.7(1.5)$ in infants with minimum triiodothyronine concentrations above $0.3 \mathrm{nmol} / 1(\mathrm{p}<0.01)$. For the analyses below, subjects were grouped according to whether their lowest triiodothyronine concentration was above or below $0.3 \mathrm{nmol} / 1$.

The relationship between mental developmental index and the lowest concentration for triiodothyronine (above or below $0.3 \mathrm{nmol} / \mathrm{l}$ ) was explored further by adjusting for sex, birth weight, gestation, small for dates status, mode of delivery, Apgar score at 5 minutes, number of days of ventilation, and maternal toxaemia. Even after these adjustments, infants whose plasma triiodothyronine fell below $0.3 \mathrm{nmol} / \mathrm{l}$ had a score that was 8.3 points lower than those whose recorded plasma triiodothyronine was consistently above this value $(p=0 \cdot 022$; table 2$)$. The only other independent variable in the model which related significantly to the mental developmental index (dependent variable) was days of ventilation $(p<0.04)$. After adjusting for the factors

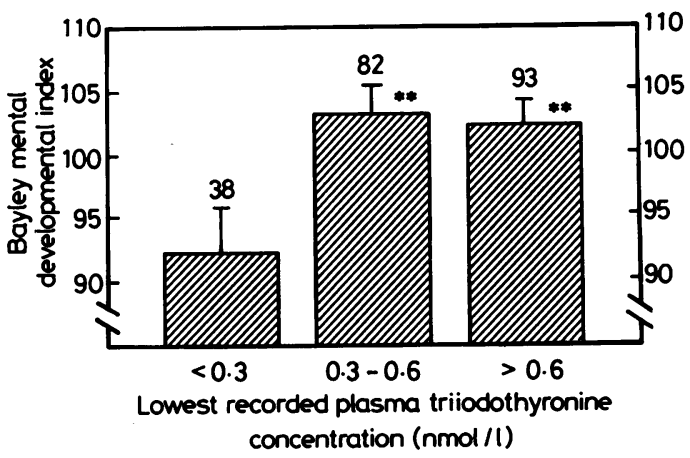

Fig 2 Relationship between the lowest recorded value of plasma triiodothyronine concentration and Bayley mental developmental index at 18 months' corrected age.

Triiodothyronine concentrations are divided into three categories: (i) $<0.3 \mathrm{nmol} / \mathrm{l}$, (ii) 0.3 to $0.6 \mathrm{nmol} / \mathrm{l}$, and (iii) $>0.6 \mathrm{nmol} / \mathrm{l}$; scores for the mental development index are mean (SE) (No above each data bar). ${ }^{* *}=p<0.01$ for difference between score in category (i) and either (ii) or (iii).

Table 2 Developmental disadvantage seen in surviving preterm infants whose lowest recorded plasma triiodothyronine concentration fell below $0.3 \mathrm{nmol} / \mathrm{l}$ (compared with those with lowest plasma triiodothyronine above this value), after adjusting for birth weight, gestation, days of ventilation, sex, Apgar score at 5 minutes, and mode of delivery

\begin{tabular}{llll}
\hline $\begin{array}{l}\text { Developmental } \\
\text { test }\end{array}$ & $\begin{array}{l}\text { No of } \\
\text { subjects }\end{array}$ & $\begin{array}{l}\text { Developmental } \\
\text { disadvantage } \\
\text { (points) for } \\
\text { infants with } \\
\text { plasma tri- } \\
\text { iodothyronine } \\
\text { concentration } \\
<0.3 \text { nmolll } \\
\text { (95\% confidence }\end{array}$ & $\begin{array}{l}\text { p Value } \\
\text { (from } \\
\text { regression } \\
\text { model) }\end{array}$ \\
\hline $\begin{array}{c}\text { interval) } \\
\begin{array}{c}\text { Bayley mental } \\
\text { developmental index }\end{array}\end{array}$ & 213 & $8.3(1.1$ to 16.7) & 0.022 \\
$\begin{array}{c}\text { Bayley psychomotor } \\
\text { developmental index }\end{array}$ & 210 & $7.4(1.6$ to 13.2) & 0.012 \\
$\begin{array}{c}\text { Academic scale of } \\
\text { developmental profile } \\
\text { II (IQ equivalent) }\end{array}$ & 226 & $8.6(2.0$ to 15.2) & 0.010 \\
\hline
\end{tabular}


listed above, a minimum triiodothyronine concentration of under $0.3 \mathrm{nmol} / 1$ also predicted Bayley motor development $(7.4$ point disadvantage; $p=0.012)$ and IQ equivalent ( 8.6 point disadvantage; $p=0.010)$; the latter test (see above) permitted inclusion of infants with cerebral palsy (13 cases).

Mortality rates (up to 18 months) were significantly related to plasma triiodothyronine concentration; in infants whose triiodothyronine fell below $0.3 \mathrm{nmol} / \mathrm{l}, 14$ out of $61(23 \%)$ died, compared with 12 out of $219(6 \%)$ in those whose plasma triiodothyronine remained above this concentration (by $\chi^{2}$ test, $\mathrm{p}<0.0001$ ). After adjusting for birth weight and gestation, the increase in mortality rate in the group with a lower plasma triiodothyronine concentration was diminished but still significant $(\mathrm{p}<0.02)$; and after adjusting further for requirement for mechanical ventilation, the relationship between plasma triiodothyronine concentration and mortality was lost.

No association was found between low plasma triiodothyronine concentrations and somatic growth; the outcome responses examined included head circumference, length and weight gain in the neonatal period, and head size, length, and body weight at 18 months' corrected age (table 1 ). In addition no relationship was observed between plasma triiodothyronine concentration and necrotising enterocolitis in the neonatal period or cerebral palsy at follow up (table 1).

Plasma total protein concentration was available for all the samples analysed for triiodothyronine. The relationship between triiodothyronine and later development was not influenced by adjusting for plasma protein at the time that the sample was taken.

\section{Discussion}

The principal finding in this follow up study on 280 preterm infants was the major association between low plasma triiodothyronine concentration and later development. Infants in the study were monitored weekly for plasma triiodothyronine concentrations during their hospital stay; those whose lowest recorded value was less than $0.3 \mathrm{nmol} / \mathrm{l}$ had significantly lower scores on the Bayley mental scale, Bayley motor scale, and on the academic scale of the questionnaire based test, Developmental Profile II, even after adjustment for a range of key maternal, perinatal, and neonatal factors.

The magnitude of the association between low plasma triiodothyronine concentrations and developmental scores was surprising. Examination of raw data showed a 10.4 point disadvantage in the
Bayley mental developmental index for infants whose plasma triiodothyronine concentrations fell below $0.3 \mathrm{nmol} / 1$ (about $20 \%$ of the population studied). Even after statistical adjustment for birth weight, gestation, number of days of ventilation, and other important factors associated with impaired development, an 8.3 point disadvantage remained. Corresponding disadvantages were found (after adjustment) for motor development (7.4 points), and IQ equivalent (8.6 points). It was interesting that the latter test, which permitted inclusion of cases of cerebral palsy, gave remarkably similar results to those obtained from the Bayley mental scale, despite the fundamentally different nature of the two tests. Furthermore, in each of the three developmental tests, a low triiodothyronine concentration was the most significant factor analysed, greatly exceeding the predictive value of birth weight or gestation. Only the number of days of ventilation, in the Bayley mental developmental index, came close to a low plasma triiodothyronine concentration in this respect.

A number of investigators have raised the possibility that reduced plasma thyroid hormone concentration may play a major part in potentiating respiratory disease ${ }^{9} 10{ }^{12-14}$; in this study, however, the developmental effects observed were independent of respiratory illness (as measured by days of ventilation required).

Our data contrast with those of other workers who have not found developmental consequences of low triiodothyronine concentrations. ${ }^{19} 21$ Large sample sizes, however, are required to detect such developmental differences. From our own studies, we have calculated that the sample size required to detect an eight point difference in Bayley mental scale scores between two groups of babies (as detected here) is 150 subjects ( $<5 \%$ significance and $80 \%$ power). This could account for the absence of developmental effects seen at one year in the controlled double blind study of thyroid hormone replacement in premature babies conducted by Chowdhry et al on only 23 subjects. ${ }^{21}$

In this study we measured total triiodothyronine and not 'free' triiodothyronine. We have considered that our findings on neurodevelopment might relate to low thyroglobulin concentration, rather than to low thyroid hormone concentration in preterm infants. We did establish that total plasma protein concentration was not independently related to development, however, and that adjusting for plasma protein concentration did not influence the relationship between plasma triiodothyronine and developmental scores.

Somatic growth might be influenced by thyroid concentrations in several ways: for instance, by 
effects on energy metabolism, gut maturation, or respiratory illness (see below). We found no relationship, however, between plasma triiodothyronine concentration and head circumference, length, or weight gain in the short term; or head circumference, length, or body weight at 18 months' corrected age.

We considered that low thyroid hormone concentrations might cause an increased incidence of necrotising enterocolitis as a result of a reduced rate of gut maturation ${ }^{15}$; but no relationship between plasma triiodothyronine and necrotising enterocolitis was observed.

The death rate of infants with plasma triiodothyronine concentrations falling below $0.3 \mathrm{nmol} / 1$ was over four times higher than in those with persistently higher triiodothyronine concentrations. This association was reduced after adjusting for differences in birth weight and gestation between the groups with higher and lower plasma triiodothyronine concentrations, and was abolished after adjusting for the requirement for mechanical ventilation. This observation could be interpreted as an indirect effect of low plasma triiodothyronine concentration on mortality, through potentiation of respiratory disease, which is the major cause of death in preterm infants. This concept is supported by a body of experimental data on the effects of thyroid hormones on surfactant synthesis and lung maturation. ${ }^{12-14}$ Indeed, in this study, after adjustment for other factors, there was a strong correlation between low triiodothyronine and duration of respiratory assistance, though whether or not low triiodothyronine concentration is a cause or effect of lung disease in preterm infants is still unresolved.

Whether aspects of the routine management of preterm infants influence plasma triiodothyronine concentrations, is currently under investigation. Our preliminary (unpublished) studies suggest that the incidence of very low plasma triiodothyronine concentrations, that are seen in some babies, may be independently related to low nutrient intakes. Conversely, maternal treatment with steroids appeared to have a prophylactic effect on the occurrence of plasma triiodothyronine concentrations under 0.3 nmol/l.

Our data confirm, on a large cohort, that preterm infants frequently have low plasma triiodothyronine concentrations in the postnatal period; and the pattern of postnatal changes has been defined for reference purposes. Previous reference values for triiodothyronine have often been based on relatively large, well, premature babies, and from one such study a value of $0.7 \mathrm{nmol} / \mathrm{l}$ could be taken as a lower limit of the range. ${ }^{5} \mathrm{By}$ the fourth week $100 \%$ of well, non-ventilated preterm infants over $1500 \mathrm{~g}$ birthweight in this study had exceeded that value; but of the infants below $1200 \mathrm{~g}$, only $41 \%$ had exceeded it (34\% in those who were ventilated), and $24 \%$ had still not attained this value by the eighth week.

There is still considerable debate on whether preterm infants, especially those who are sick or of very low birth weight, should receive routine treatment with thyroid hormones. In favour of this approach are the known, major adverse consequences of thyroid hormone deficiency in other circumstances. Against it are the arguments that 'hypothyroxinaemia of prematurity' may not have the same pathophysiological importance as in older subjects, and that a pharmacologically induced increase in metabolic rate might dissipate critical energy reserves and raise the requirement for oxygen. Furthermore, thyroid hormones are potent biological triggers, which could have unpredictable effects if given unnecessarily. The disappointing results from some outcome studies may have added further weight to these counter arguments. ${ }^{19} 21$ While low plasma triiodothyronine concentration is strongly predictive of developmental outcome in this study, the relationship may not be causal. Nevertheless, the strength and magnitude of the association clearly warrant further investigation, and we suggest that larger intervention studies, targeted to detect realistic differences in later development, are now indicated. The children in this study are part of a larger cohort being followed up indefinitely, and we shall be able to assess the longer term significance of the poor developmental scores seen at 18 months in association with low neonatal plasma triiodothyronine concentrations.

We wish to thank Drs Bamford, Boon, Pearse, Dossetor, and Crowle for their help in the neonatal units at Ipswich, Sheffield, Norwich, and King's Lynn, and Farley Health Products Limited for financial help.

\section{References}

${ }^{1}$ Chopra IJ, Sack J, Fisher DA. Reverse T3 in the fetus and newborn. In: Fisher DA, Burrow GN, eds. Perinatal thyroid physiology and disease. New York: Raven Press, 1975:33-48.

2 Abuid J, Klein AH, Foley TP Jnr, et al. Total and free triiodothyronine and thyroxine in early infancy. J Clin Endocrinol Metab 1974;39:263-8.

3 Montalvo JM, Wahner HW, Mayberry WE, et al. Serum triiodothyronine, total thyroxine and thryoxine to triiodothyronine ratios in paired maternal-cord sera at 1 week and 1 month of age. Pediatr Res 1973;7:706-11.

${ }^{4}$ Fisher DA, Klein AH. Thyroid development and disorders of thyroid function in the newborn. N Engl J Med 1981;304:70211 .

5 Brock Jacobsen B, Hummer L. Changes in serum concentrations of thyroid hormones and thyroid hormone-binding proteins during early infancy. Acta paediatr Scand 1979;68:411-8.

${ }^{6}$ Brock Jacobsen BB, Andersen HJ, Peitersen B, Dige-Petersen H, Hummer L. Serum levels of thyrotrophin, thyroxine and 
triiodothyronine in full term, small for gestational age and preterm newborn babies. Acta Paediatr Scand 1977;66:681-7.

7 Franklin RC, Purdie GL, O'Grady C. Neonatal thyroid function: prematurity, prenatal steroids, and respiratory distress syndrome. Arch Dis Child 1986;61:589-92.

${ }^{8}$ Etling N, Padovani E, Gehin-Fouque F, Tato L. Serum and urine thyroid hormone levels in healthy preterm and small for date infants on the first and fifth day of life. Helv Paediatr Acta 1984;39:223-30.

9 Dhanireddy R, Smith YF, Hamosh M, et al. Respiratory distress syndrome in the newborn: relationship to serum prolactin, thyroxine and sex. Biol Neonate 1983;43:9-15.

10 Brock Jacobsen B, Peitersen B, Hummer L. Serum concentrations of thyrotrophin, thryoid hormones and thyroid hormonebinding proteins during acute and recovery stages of idiopathic respiratory distress syndrome. Acta Paediatr Scand 1979;68:25764.

11 Vermak WJH, Kalk WJ, Zakolski WJ. Frequency of the euthyroid sick syndrome as assessed by free thyroxine index and a direct free thyroxine assay. Lancet 1983;i:1373-6.

12 Wu B, Kikkawa Y, Orzalesi MM, et al. Accelerated maturation of fetal rabbit lungs by thyroxine. Physiologist 1971;14:253.

13 Redding RA, Douglas WHJ, Stein M. Thyroid hormone influence upon lung surfactant metabolism. Science 1972;175:994-6.

14 Erenberg A, Omori K, Menkes, et al. Growth and development of the thyroidectomized ovine fetus. Pediatr Res 1974;8:783-9.

${ }^{15}$ Lebenthal E, Lee PC. Interaction of determinants in the ontogeny of the gastrointestinal tract: a unified concept. Pediatr Res 1983;17:19-24.

16 Anderson HJ. Prenatal damage in hypothyroidism. In: Hamburgh M, Barrington EJW, eds. Hormones in development. New York: Appleton-Century-Crofts, 1971:559-66.
${ }^{17}$ Brasel JA, Boyd D. Influence of thyroid hormones on fetal brain growth and development. In: Fisher DA, Burrow GN, eds. Perinatal thyroid physiology and disease. New York: Raven Press, 1975:59-71.

18 Eayrs JT. Thyroid and developing brain: Anatomical and behavioural effects. In: Hamburgh M, Barrington EJW, eds. Hormones in development. New York: Appleton-CenturyCrofts, 1971:345-55.

19 Hadeed AJ, Asay LD, Klein AH, et al. Significance of transient hypothyroxinaemia in premature infants with and without respiratory distress syndrome. Pediatrics 1981;68:494-8.

${ }^{20}$ Schonberger W, Grimm W, Emmrich P, Gemp W. Reduction of mortality rate in premature infants by substitution of thyroid hormones. Eur J Pediatr 1981;135:245-53.

${ }^{21}$ Chowdhry P, Scanlon JW, Auerbach R, et al. Results of controlled double-blind study of thyroid hormone replacement in very low birthweight premature infants with hypothyroxinaemia. Pediatrics 1982;73:301-5.

22 Lucas A, Gore SM, Cole T, et al. Multicentre trial on feeding low birthweight infants: effects of diet on early growth. Arch Dis Child 1984;59:722-30.

${ }^{23}$ Bayley N. The Bayley scales of infant development. New York: The Psychological Corporation, 1969.

${ }^{24}$ Alpern GD, Boll TJ, Shearer Ms. Developmental profile II. Aspen, Colorado: Psychological Development Publications, 1980.

Correspondence to Dr A Lucas, Dunn Nutritional Laboratory, Downhams Lane, Milton Road, Cambridge CB4 1XJ.

Accepted 23 March 1988 